\title{
Implementation of a High Efficiency Grid-Tied Multi-Level Photovoltaic Power Conditioning System Using Phase Shifted H-Bridge Modules
}

\author{
Jong-Pil Lee ${ }^{\dagger}$, Byung-Duk Min ${ }^{* *}$, and Dong-Wook Yoo* \\ $\dagger^{\dagger *}$ Power Conversion Research Center, Korea Electrotechnology Research Institute, Changwon, Korea \\ ${ }^{* *}$ Green Power Co. Ltd, Suwon, Korea
}

\begin{abstract}
This paper proposes a high efficiency three-phase cascaded phase shifted H-bridge multi-level inverter without DC/DC converters for grid-tied multi string photovoltaic (PV) applications. The cascaded H-bridge topology is suitable for PV applications since each PV module can act as a separate DC source for each cascaded H-bridge module. The proposed phase shifted H-bridge multi-level topology offers advantages such as operation at a lower switching frequency and a lower current ripple when compared to conventional two level topologies. It is also shown that low ripple sinusoidal current waveforms are generated with a unity power factor. The control algorithm permits the independent control of each DC link voltage with a maximum power point for each string of PV modules. The use of the controller area network (CAN) communication protocol for H-bridge multi-level inverters, along with localized PWM generation and PV voltage regulation are implemented. It is also shown that the expansion and modularization capabilities of the H-bridge modules are improved since the individual inverter modules operate more independently. The proposed topology is implemented for a three phase $240 \mathrm{~kW}$ multi-level PV power conditioning system (PCS) which has 40kW H-bridge modules. The experimental results show that the proposed topology has good performance.
\end{abstract}

Key words: H-bridge multilevel inverter, Photovoltaic PCS (Power Conditioning System)

\section{INTRODUCTION}

In recent years, renewable energy resources have become an increasingly important part of power generation. Aside from assisting in the reduction of the emission of greenhouse gases, they add much needed flexibility to the energy resource mix by decreasing the dependence on fossil fuels. Due to their modular characteristics and ease of installation and because they can be located closer to users, PV systems have great potential as a distributed power source [1]. The focus is to make use of abundantly available PV energy through the design and control of an inverter suitable for photovoltaic applications.

Manuscript received Sep. 26, 2012; revised Jan. 14, 2013

Recommended for publication by Associate Editor Sung-Yeul Park.

${ }^{\dagger}$ Corresponding Author: jplee@keri.re.kr

Tel: +82-55-280-1418, Fax: +82-55-280-1449, KERI

*Power Conversion Research Center, Korea Electrotechnology Research Institute, Korea

${ }^{* *}$ Green Power Co. Ltd, Korea
Many topologies for large scale PV generation systems have been proposed in the literature [2]-[7]. Fig. 1 shows the general topology of a large scale PV generation system. The central PV generation system is shown in Fig.1 (a). It is widely used in large scale PV generation systems because of its cost effectiveness. However, it has a drawback under shading conditions. Fig 1(b) shows the string topology which consists of series-connected PV strings with a general DC/AC inverter. The string PCS can avoid most of the drawbacks of the central PCS. The generation efficiency is higher than that of a central generation system due to its ability to adopt a MPPT controller to each individual string. The mismatch problem of parallel-connected strings is avoided under shading conditions. However, it has a power limit due to its limited number of series connections in order to increase the nominal power. To avoid this problem, the multi-string topology was proposed as shown in Fig. 1(c). It consists of several PV strings that connect DC/DC converters to a general DC/AC inverter. The multi-string PCS has the advantages of the central PCS and the string PCS: no 


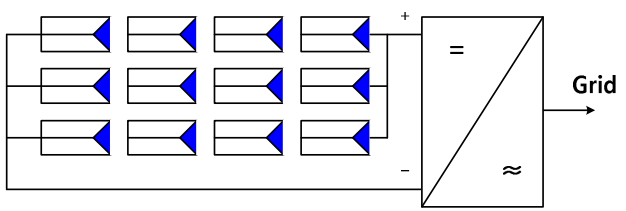

(a) Central topology.

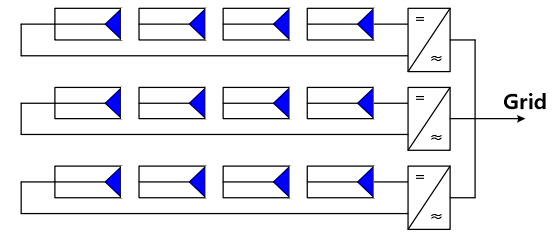

(b) String topology.

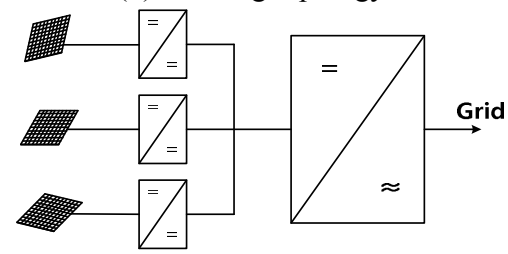

(c) Multi string topology.

Fig. 1. Topologies of large scale PV generation system.

mismatch problem of the parallel-connected strings, no partial shading problem, no nominal power limitation, etc [21]. However, it is a two stage power conversion topology which means low efficiency. To increase the power conversion efficiency, a novel multi string PCS topology is needed.

These days, multi-level inverter topologies have been considered for photovoltaic applications. A multi-level inverter can generate low harmonic voltage waveforms with a low switching frequency. Additionally, the multi-level topology has several DC links which makes it possible to control the voltage independently with MPPT in each string. In addition, this characteristic makes it possible to increase the PV generation efficiency in the case of partial shading due to unbalanced solar radiation. Among multi-level topologies, the cascaded phase shifted H-bridge topology has several advantages such as a PV PCS. That is, an output voltage synthesis with a higher number of levels. This number of levels grows according to the number of series-connected modules in the converter. This topology can make a modular design and has power semiconductors with a lower rating than the conventional two level topology. This leads to cost savings. In [8][9], a single phase cascaded H-bridge multi-level inverter has been presented. However, it does not describe a large scale three phase PV PCS system.

This paper proposes a high efficiency cascaded H-bridge multi-level topology for large scale grid-tied three-phase multi-string PV systems. The use of MPPT algorithms that independently control the DC link voltages is applied for the control of the three-phase cascaded H-bridge multi-level converter. In addition, The use of the controller area network (CAN) communication protocol for H-bridge multi-level inverters, along with localized PWM generation and PV

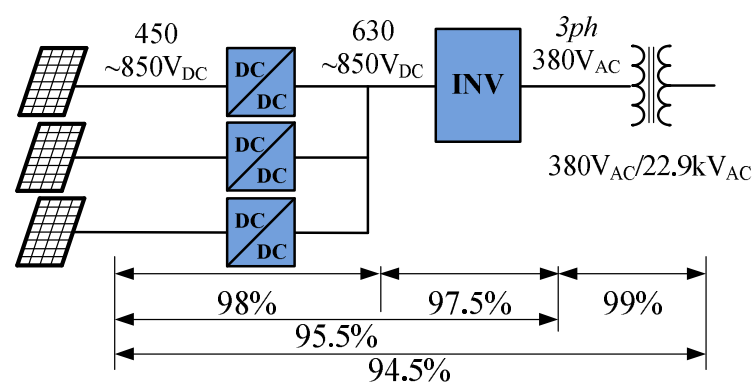

(a) Conventional topology(DC/DC converter + Inverter).

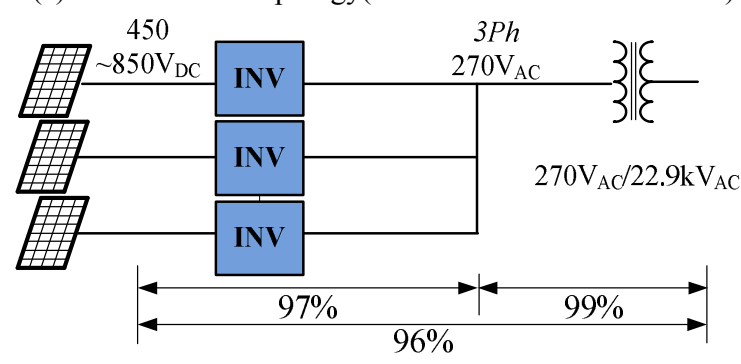

(b) Single stage topology.

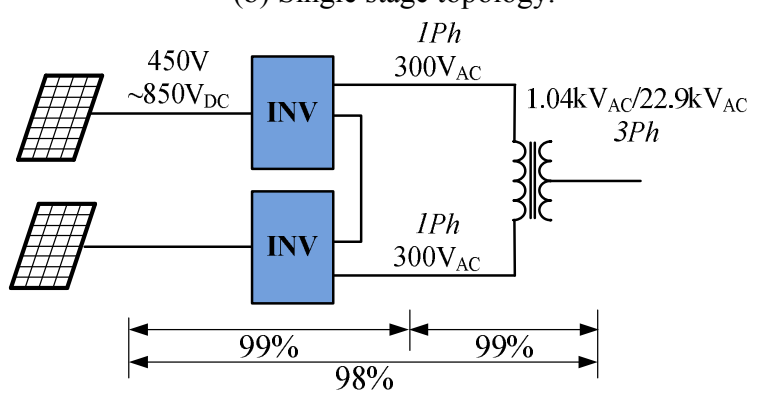

(c) Proposed cascaded H-bridge topology.

Fig. 2. PV PCS schemes for multi string topology.

voltage regulation are implemented. It is also shown that the expansion and modularization capabilities of the H-bridge modules are improved since the individual inverter modules operate more independently. The validity of the proposed system is verified experimentally on a three-phase $240 \mathrm{~kW}$ cascaded H-bridge multi-level PV PCS.

\section{CHARACTERISTICS OF MULTI-LEVEL INVERTERS FOR PV APPLICATIONS}

The multi-level inverters for PV applications have several dc links, making possible independent voltage control and tracking of the maximum power point (MPP) in each string.

The characteristics of the multi-level inverters for $\mathrm{PV}$ applications can increase the generation efficiency of the PV system in the case of a mismatch in the string, due to unequal solar radiation, aging of the PV modules, different types of cells, or the accumulation of dust on the surface of the modules [10]-[16]. The cascaded H-bridge multi-level inverter is an interesting conversion topology among the available multi-level inverters because of its modularity, simple layout, and reduced number of components. The major drawback of this topology is the large number of distinct dc links. However, it is suitable for multi-string PV 


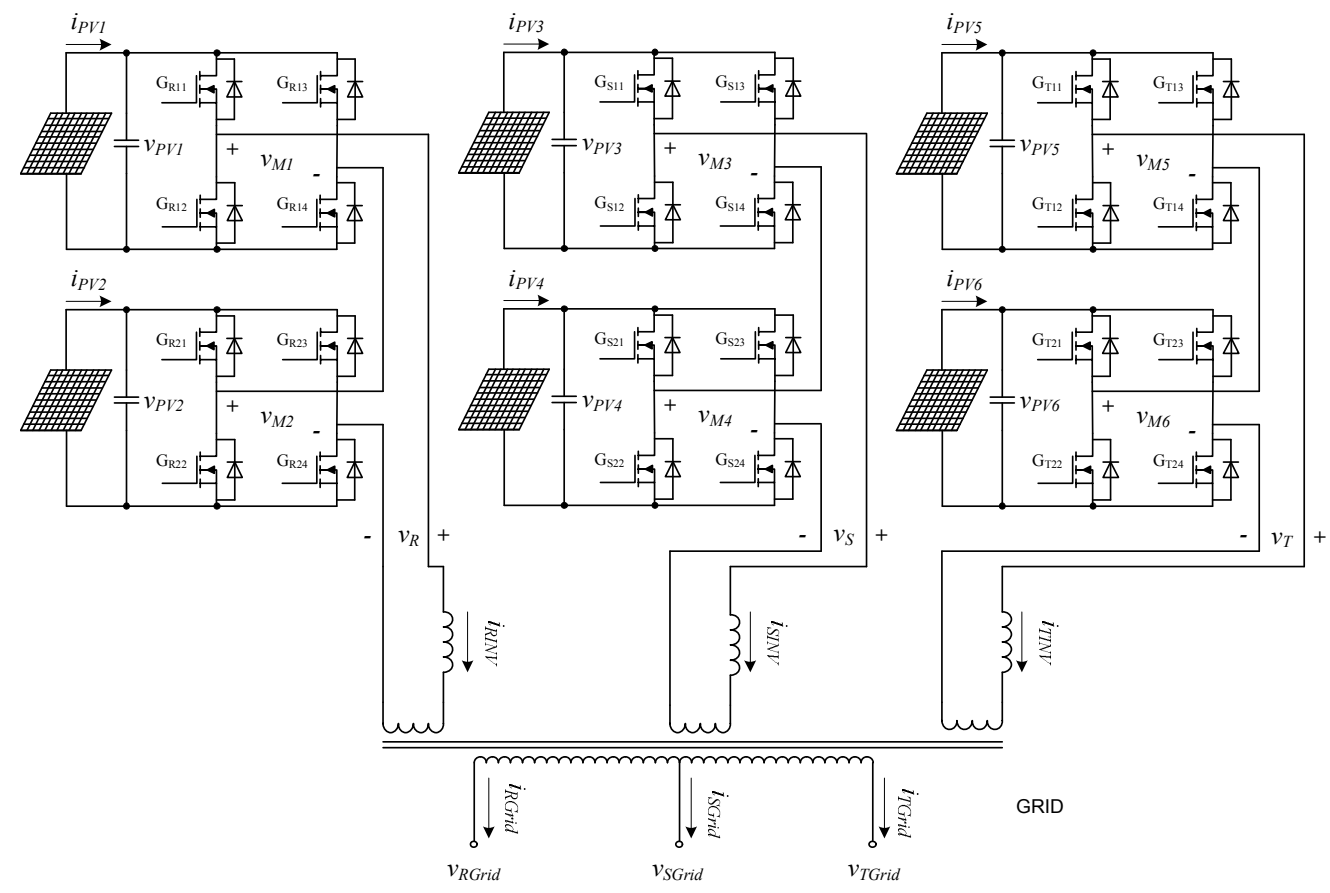

Fig. 3. Proposed three phases cascaded H-bridge PV PCS.

systems as a PV PCS.

The conventional PV PCS scheme for the multi-string topology is shown in Fig. 2(a). It consists of a DC/DC converter for each of the PV modules and the grid-tied inverter. If it is supposed that the efficiency of the DC/DC converters is $98 \%$, the efficiency of the inverter is $97.5 \%$, and the efficiency of the transformer is $99 \%$, then the efficiency of the system is about $94.5 \%$ [23].

The conventional scheme has a low efficiency and is not a suitable topology for large PV generation systems due to its two stage conversion topology. Fig. 2(b) shows a single stage multi-string topology with a parallel-connected inverter. The conversion efficiency is higher than the conventional system due to its single conversion. However, it has a power limit due to its limited number of series connections in order to increase the nominal power. To overcome this problem, a novel multi string PCS is in need of a high efficiency and effective cascaded H-bridge inverter topology without a DC/DC converter, as shown in Fig. 2(c). This topology has only cascaded inverters with a high output voltage in each phase. The proposed transformer turn ratio is $1.04 \mathrm{KV} / 22.9 \mathrm{KV}$ with a high efficiency.

As a result, the efficiency of this topology achieves $98 \%$. Nevertheless, it is in need of an independent MPPT control algorithm with grid current control. The proposed topology is presented in the next section. The advantages of the proposed multi-string construction using the H-bridge topology are listed as follows: 1) 5-level inverter output voltage; 2) reduced switching loss; 3) small size filter inductor and transformer; 4) low THD current waveforms; and 5) better efficiency than the conventional multi-level topology.

\section{PROPOSED TOPOLOGY DESCRIPTION}

Fig. 3 shows that the proposed three phase cascaded H-bridge multi-string PV PCS uses a multi-level topology which has an independent MPPT operation for each of the PV modules [17]. The proposed topology has a 5-level PWM switching waveform which reduces the switching frequency better than the conventional topology.

\section{A. PWM Scheme with the Phase Shift Unipolar Method}

Many PWM techniques have been proposed over years for multi-level inverters [18]. Among these, the methods based on sine-triangular comparison take a great part, including carrier phase-shifted PWM schemes (PS-PWM), carrier disposition PWM schemes (CD-PWM), and compound carrier disposition PWM schemes (CCD-PWM). The PS unipolar sinusoidal PWM (PS SPWM) switching schemes, which are used in this paper, are described with the aid of Fig. 4 for a two layer H-bridge multi-level inverter.

The multi-carrier PWM method is based on a comparison of a sinusoidal reference waveform with vertically shifted carrier signals. The method uses $N-1$ level carrier signals to generate the $N$-level inverter output voltage. In multi-level inverters, the frequency modulation index, $m_{f}$, and the amplitude modulation index, $m_{a}$, are defined as:

$$
\begin{gathered}
m_{f}=\frac{f_{c a r}}{f_{r e f}} \\
m_{a}=\frac{A_{r e f}}{(N-1) A_{c a r}}
\end{gathered}
$$




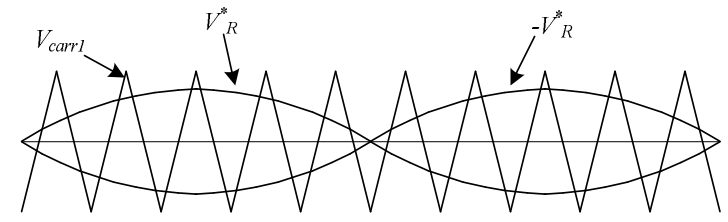

$G_{R 11}$

$G_{R 13}$

$V_{M 1}$

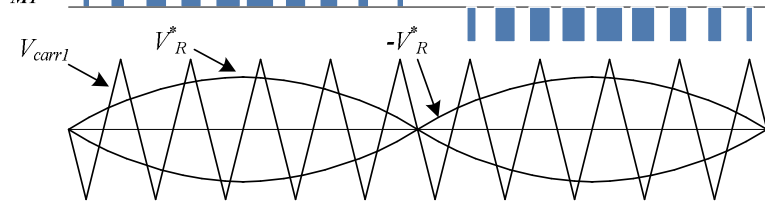

$G_{R 21}$

$G_{R 23}$

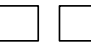

(

$\square \square$

[1]

$V_{M 2}$

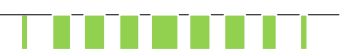

\section{$V_{R}$}

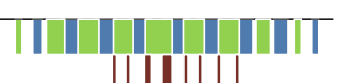

Fig. 4. Phase shifted unipolar PWM scheme for the proposed multi-level inverter.

Where $A_{c a r}$ is the amplitude of the carrier signal; $f_{c a r}$ is the frequency of the carrier signal; $A_{\text {ref }}$ is the amplitude of the reference signal; and $f_{\text {ref }}$ is the frequency of the reference signal. The H-bridge topology has a left leg and a right leg. The frequency of the output voltage waveform of the H-bridge topology is double each leg of the PWM switching frequency. The phase shift between the upper H-bridge and the lower H-bridge is 90 degree. It could be double the switching frequency of each H-bridge. In addtion, the output voltage of the two H-bridge topology is a 5-level waveform $\left(V_{R}\right)$ as shown in Fig. $4\left(m_{f}=35, m_{a}=0.8\right)$. One of the main advantages of this PWM scheme is that the harmonics of the resultant H-bridge multi-level inverter output voltage only appear as sidebands centered around the frequency of $2 \mathrm{Nfs}$ and its multiples ( $\mathrm{N}$ is the number of single-phase inverters, and $\mathrm{fs}$ is the frequency of the triangle carrier signals). Therefore the H-bridge multi-level inverter output voltage has a very high equivalent switching frequency, even if the switching frequency of the individual switches is not so high.

\section{B. Control Scheme}

The structure of the multi-level inverter for the PV PCS has various PV modules but a single phase current output. Therefore, it can not apply a general MPPT algorithm [13]-[15]. The control algorithm for the proposed topology controls the output current and several of the input voltages simultaneously [8][9]. One of them is used to adjust the capacitor voltage in each of the dc links, and the other one is necessary for the generation of a sinusoidal input current with a unity power factor.

Fig. 5 shows the control algorithm of the proposed n-level H-bridge inverter with a single phase. The P\&O (Perturb \& Observe) method applies the MPPT algorithm. The output of MPPT function block is the input reference voltage $\left(V_{P V 1}^{*}, V_{P V 2}^{*}, . ., V_{P V n}^{*}\right)$, where $V_{P V n}^{*}$ is the input reference voltage of the n-th $\mathrm{H}$-bridge, and $V_{P V}^{*}$ is the sum of the input reference voltages of the H-bridges. The modulation index of the n-th H-bridge $\left(V_{C O N n}\right)$ is the output of the voltage controller directly.

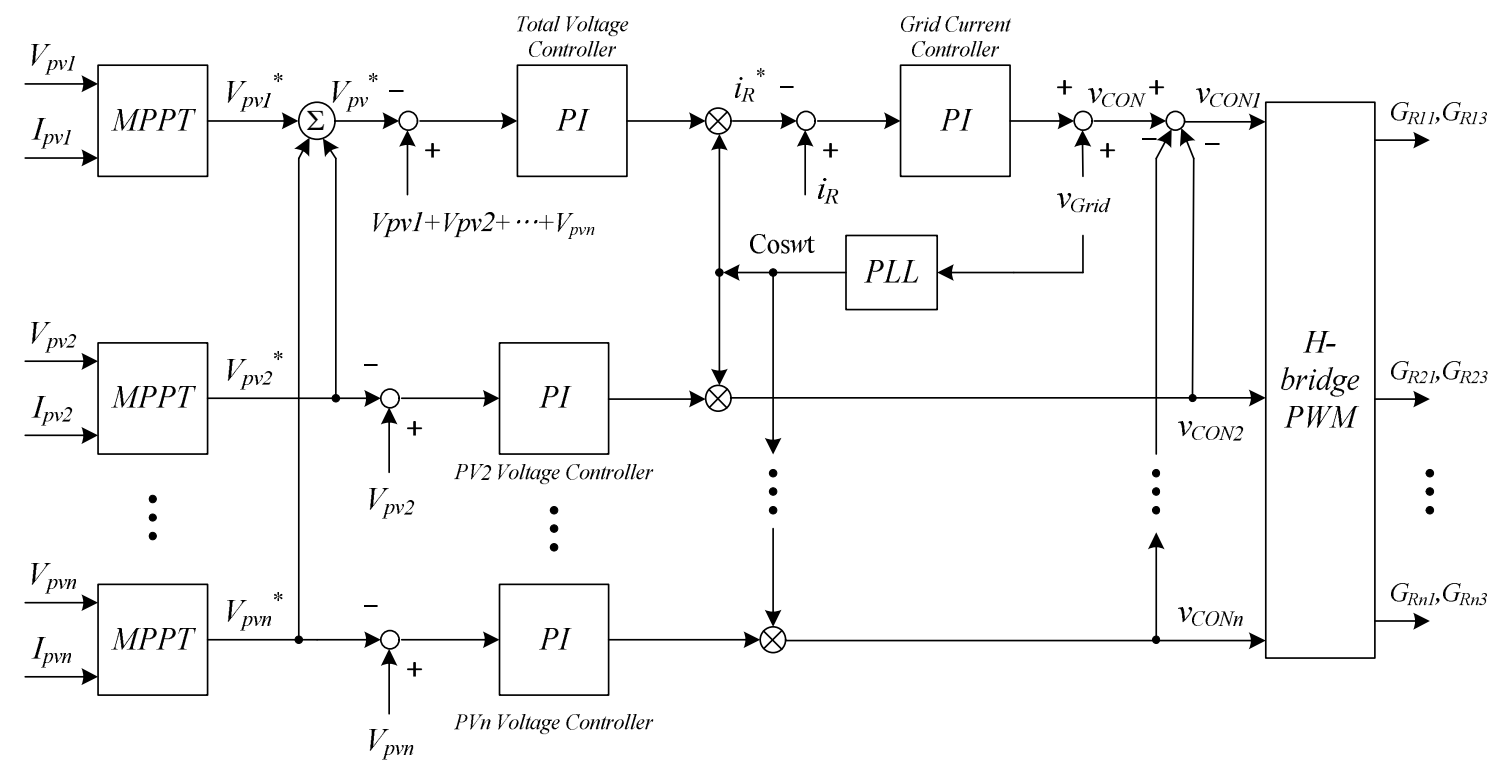

Fig. 5. Control scheme per phase of the proposed topology. 


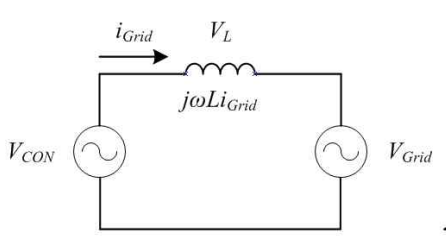

(a)

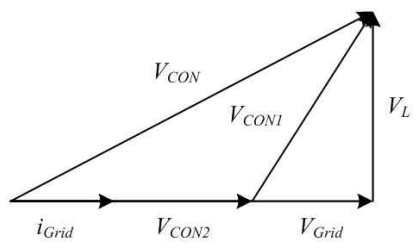

(b)

Fig. 6. Equivalent circuit of grid-connected PCS(a) and phasor diagram(b).
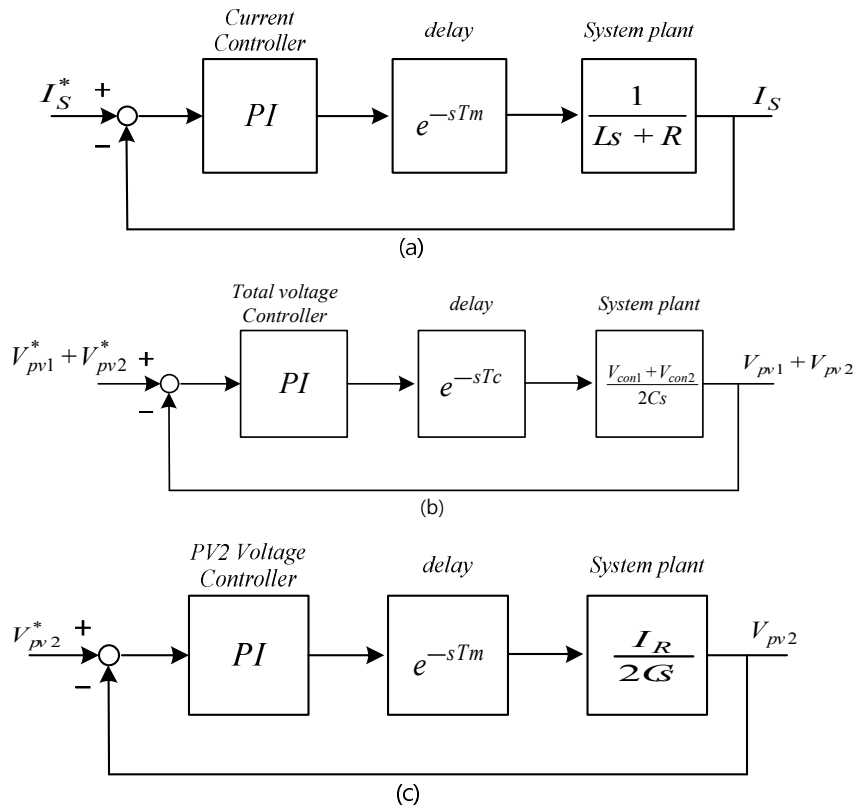

Fig. 7. Control loop (a) Current (b) Total voltage (c) $V_{p v 2}$ voltage.

The reference PV voltage $\left(V_{P V}{ }^{*}\right)$ is the sum of all of the outputs of the MPPT function block, and the output of the voltage controller of the first $\mathrm{H}$-bridge is the reference current controller. The modulation index of the first H-bridge $\left(V_{\mathrm{CONI}}\right)$ subtracts the total of each of the voltage controllers $\left(V_{C O N 1}, V_{C O N 2}, . ., V_{C O N n}\right)$ from the output of the current

TABLE I

CONTROLLER PARAMETERS

\begin{tabular}{|c|c|c|}
\hline Controller & P gain & I gain \\
\hline Grid controller & 0.06 & 0.0035 \\
\hline Total voltage & 0.3 & 0.002 \\
\hline$V_{P V 2}$ voltage & 0.27 & 0.003 \\
\hline
\end{tabular}

controller $\left(V_{C O N}\right)$.

The power factor can be controlled by changing the magnitude and phase of the voltage of each of the PV cells, as shown Fig. 6. A unity power factor is obtained when a voltage $V_{L}$ with a phase of $90^{\circ}$, with respect to the grid voltage, is generated.

\section{Controller Design}

In this control scheme, two PI controllers are necessary for independent control of each of the dc-link voltages and one PI controller is necessary for grid current control. The tuning procedure for the three control loops in Fig. 7 is described [8][9].

Fig. 7(a) shows the simplified control scheme of the current control loop. The dymanic of the current loop is much faster than the voltage loop.

The current controller was designed using a bandwidth of $400 \mathrm{rad} / \mathrm{s}$ which is high enough to provide an adequate current tracking and to filter the harmonics of the modulation. The voltage controllers were designed considering the frequency of the MPPT algorithm, which, in this case, is equal to $5 \mathrm{~Hz}$. For these controllers, a bandwidth between 50 and 200rad/s was considered.

The discrete PI control parameters used in simulation and the experimental results are described in Table I.

\section{Implementation of the Proposed Method}

In this paper, the PWM signal is generated in each of the individual modules. Therefore, the PWM signals must be synchronized. The PWM of each module is synchronized

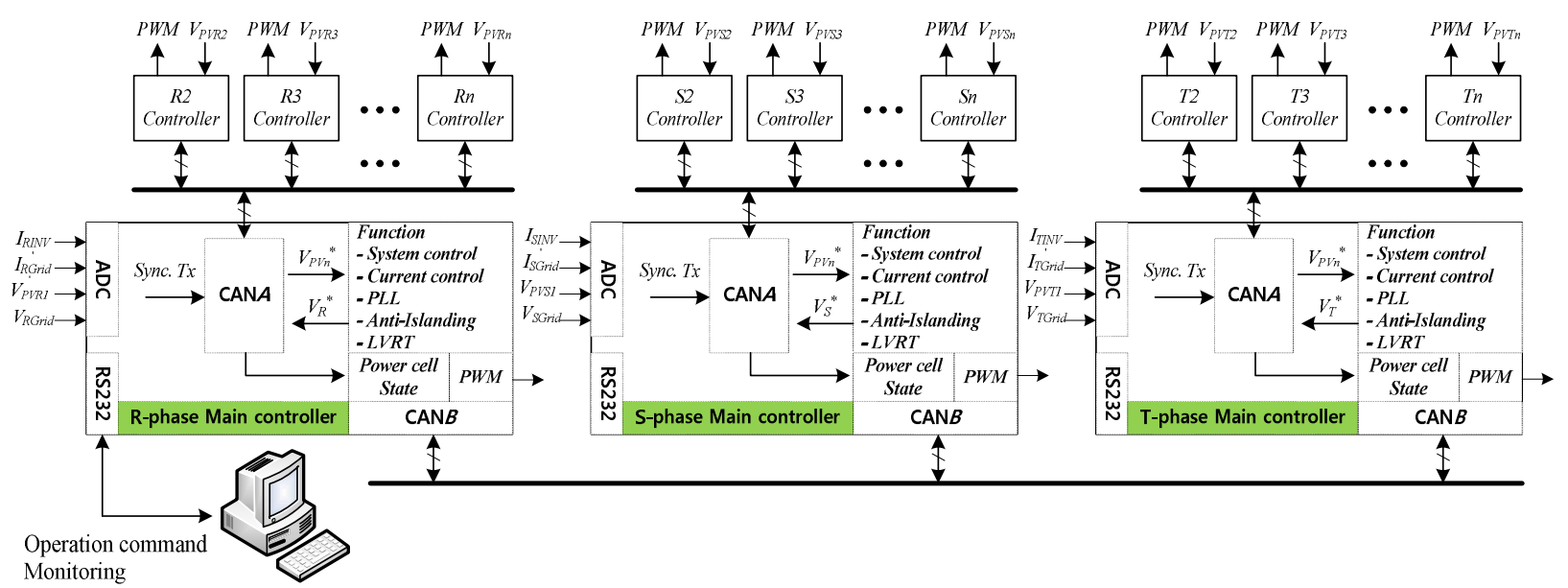

Fig. 8. System Control block diagram of proposed topology. 
TABLE II

THE SPECIFICATION OF 240KW H-BRIDGE MULTI-LEVEL PV PCS

\begin{tabular}{|c|c|}
\hline MPPT range (H-bridge module) & $400 \sim 800 \mathrm{Vdc}$ \\
Rated Power & $240 \mathrm{~kW}$ \\
Inverter output voltage/current & $880 \mathrm{Vrms} / 160 \mathrm{Arms}$ \\
Grid voltage/current & $380 \mathrm{Vrms} / 380 \mathrm{Arms}$ \\
Filter Inductance & $600 \mathrm{uH}$ \\
Switching frequency & $2.1 \mathrm{KHz}$ \\
Transformer & $880 \mathrm{~V}(\mathrm{Y}) / 380 \mathrm{~V}(\triangle)$ \\
\hline
\end{tabular}

using the CAN communication receive interrupt. The overall system control configuration and the features of the phase controller, the CAN communication, and the inverter modules are summarized in Fig. 8. The Main phase controller includes the system control, the phase current control, the PLL control, and the anti-islanding control. It also performs state monitoring, diagnosis, and communication functions. The module controller has a maximum power point tracking algorithm using an incremental conductance method. It also controls the phase shift and the required PWM voltage calculated by the main controller. Each module controller is connected to the main controller via a high speed link that is made of an optical cable.

\section{EXPERIMENTAL STUDY}

\section{A. System Configuration}

A $240 \mathrm{~kW}$ three-phase two-layer cascaded H-bridge multi-level inverter has been manufactured for testing purposes, as shown in Fig. 9(a). The two modules per output phase can be seen in a photograph of the hardware used for the experimental evaluation in Fig. 9(b).

\section{B. Experimental Results}

Fig. 10 shows the inverter output and the PWM waveforms of the upper/lower H-bridge modules. The proposed topology consists of two H-bridge modules per phase. The inverter output voltage is a 5 level waveform.

Fig 11(a) shows that the output voltage waveform of the H-bridge topology is double each leg of the PWM switching frequency. The phase shift between the upper H-bridge and the lower H-bridge is 90 degrees. It can be twice the switching frequency of each H-bridge. In addition, the output voltage of the two H-bridge topology is a 5-level waveform, as shown Fig. 11(b).

Fig. 12 shows the tracking of the MPP curve under different operating points of the PV module. The maximum power point of PV1 is $14.8 \mathrm{KW}$ and that of PV2 is $30.28 \mathrm{KW}$. The independent MPPT control algorithm works properly under different operation conditions.

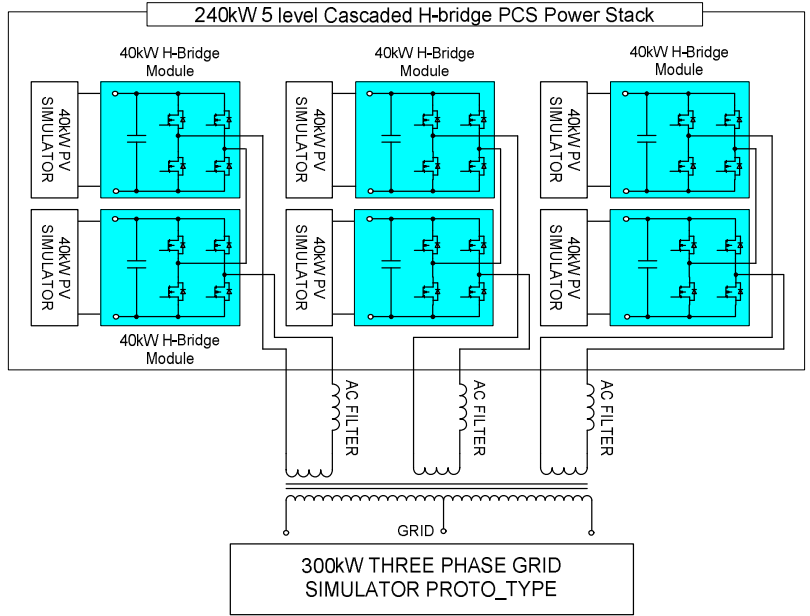

(a) Schematic of 240kW H-bridge 5-level PV PCS.

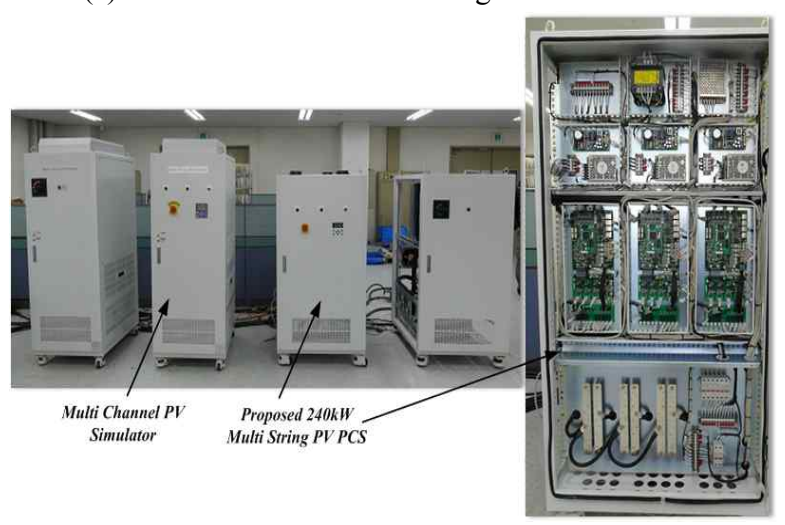

(b) $240 \mathrm{~kW}$ H-bridge 5-level inverter stack.

Fig. 9. Configuration of 240kW Proposed topology.

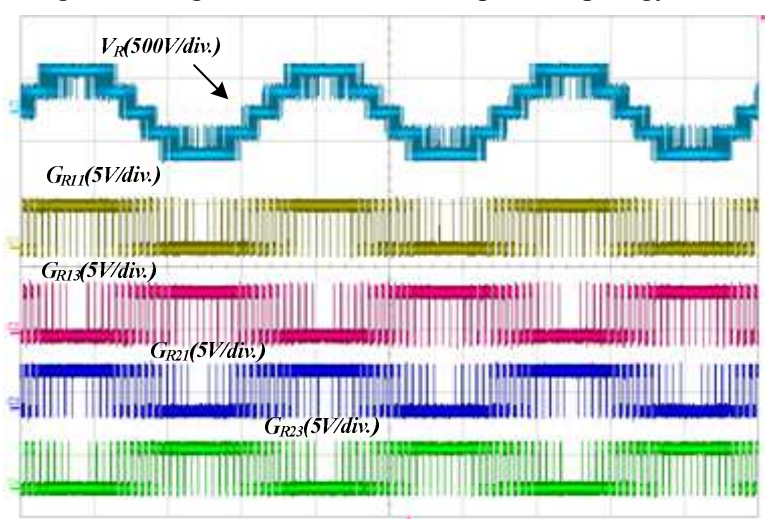

Fig. 10. The inverter output voltage and PWM waveforms (5ms/div.)

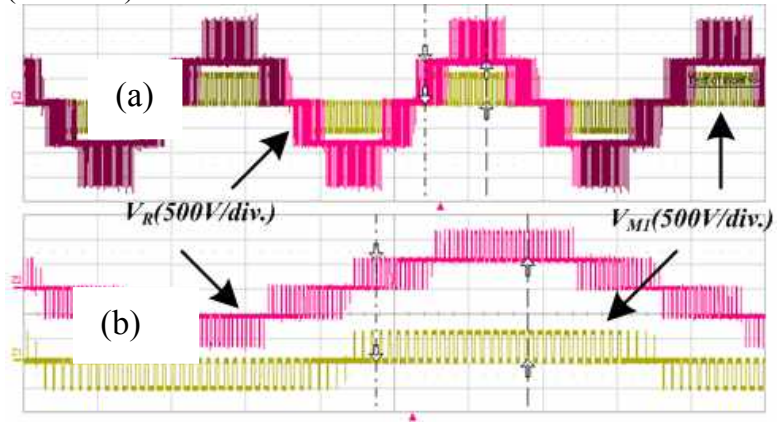

Fig. 11. The H-bridge output voltage waveforms $(5 \mathrm{~ms} / \mathrm{div}$.). 

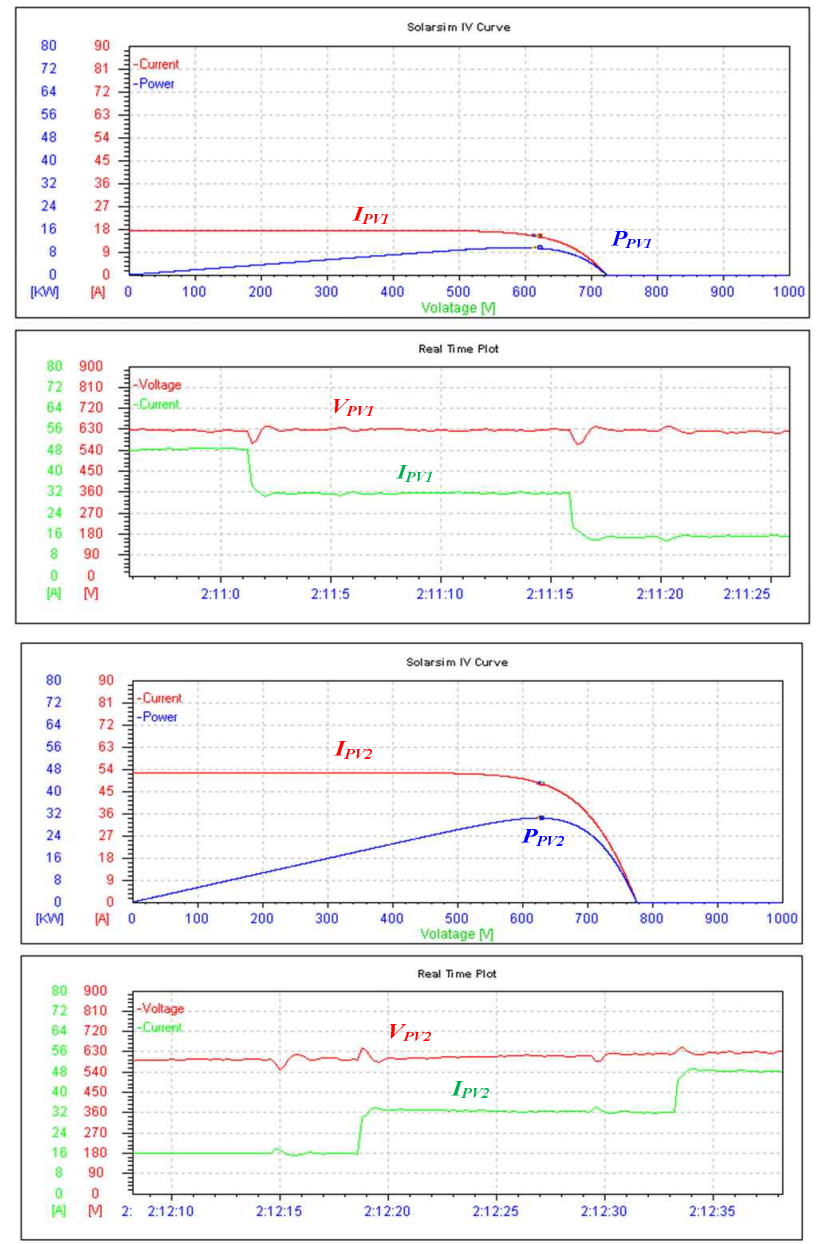

Fig. 12. MPP curve of each H-bridge PV module $\left(P V_{l}, P V_{2}\right)$.

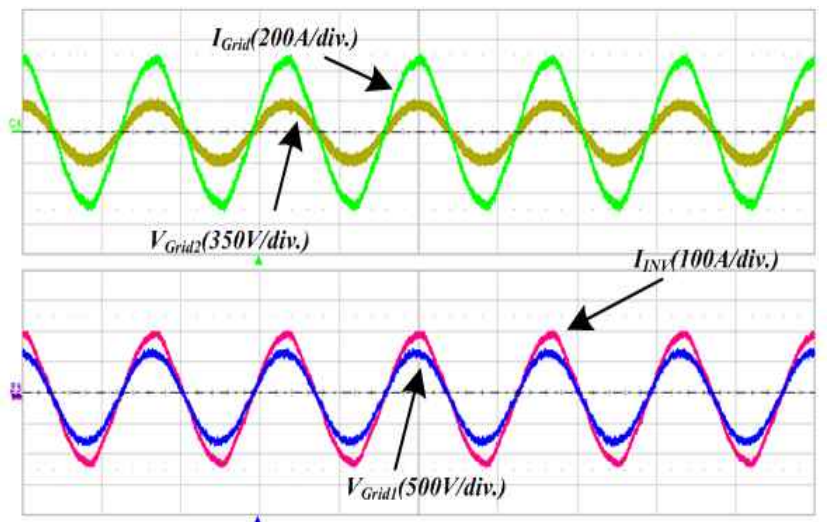

Fig. 13. Grid/Inverter voltage and current(10ms/div.).

Fig. 13 shows the experimental waveforms of the grid voltage and output current of the PCS at $240 \mathrm{~kW}$ PCS output. The THD $i$ of the output current of the PCS is $2.5 \%$ at $3.8 \%$ $\mathrm{THD} v$ of the grid voltage. The power factor is $99.8 \%$.

Fig. 14 shows the efficiency curves with respect to the input voltage $(400 \sim 800 \mathrm{Vdc})$ and the load condition $(10 \sim 100 \%)$. The peak efficiency of the proposed PCS is $99.1 \%$ without the grid transformer ( $98 \%$ with the grid transformer).

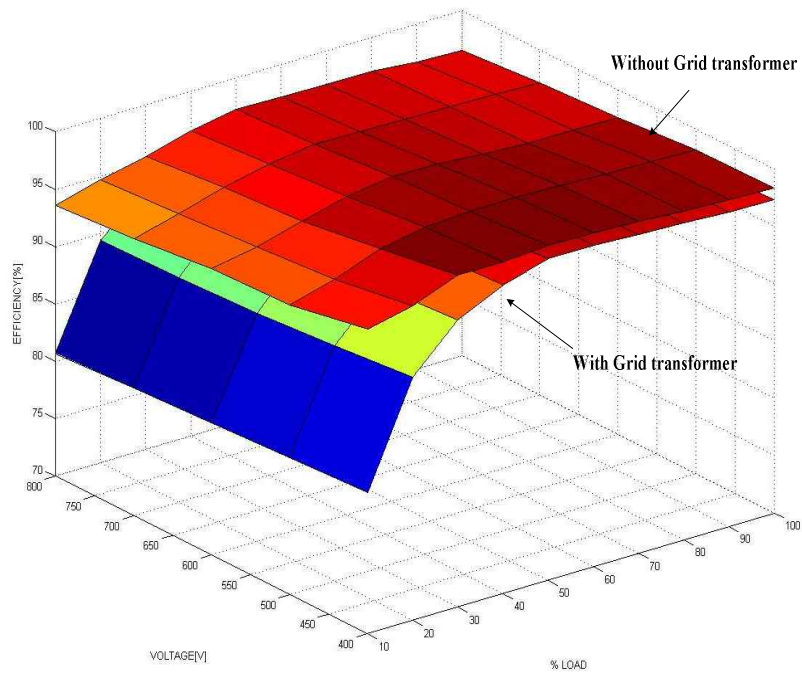

Fig. 14. Efficiency curve of the proposed PCS.

\section{CONCLUSIONS}

In this paper, a novel topology has been proposed for a PV PCS using a 5-level Phase shifted H-bridge topology with a very high efficiency. The proposed topology greatly reduces the current THD and the filter size while increasing the system efficiency. European system efficiency is up to $97.8 \%$ and peak efficiency is $99.1 \%$. The control algorithm for the proposed topology controls the output current with a unity power factor, and the upper and lower PV input voltages by adding a MPPT algorithm simultaneously. In addition, control and state monitoring among each of the phase controllers is implemented using the controller area network (CAN) communication protocol. It has been shown that there is an improvement in the expansion and modularization capabilities in the multi-level topology. The experimental results show the good performance of the proposed topology.

\section{REFERENCES}

[1] S. Alepuz, S. Busquets-Monge, J. Bordonau, J. Gago, D. Gonzalez, and J. Balcells, "Interfacing renewable energy sources to the utility grid using a three-level inverter," IEEE Trans. Ind. Electron., Vol. 53, No. 5, pp. 1504-1511, Oct. 2006.

[2] A. Safari and S. Mekhilef, "Simulation and Hardware Implementation of Incremental Conductance MPPT With Direct Control Method Using Cuk Converter," IEEE Trans. Ind. Electron., Vol. 58, No. 4, pp. 1154- 1161, Apr. 2011.

[3] J.-P. Lee, B.-D. Min, T.-J. Kim, D.-W. Yoo, and J.-Y. Yoo, "Active frequency with a positive feedback anti-islanding method based on a robust pll algorithm for grid-connected pv pcs," Journal of Power Electronics, Vol. 11, No. 3, pp. 360-368, May 2011.

[4] E. Roman, R. Alonso, P. Ibanez, S. Elorduizapatarietxe, and D. Goitia, "Intelligent pv module for grid-connected pv systems," IEEE Trans. Ind. Electron., Vol. 53, No. 4, pp. 1122-1129, Aug. 2006.

[5] J.-P. Lee, B.-D. Min, T.-J. Kim, D.-W. Yoo, and J.-Y. Yoo, "A novel topology for photovoltaic $\mathrm{dc} / \mathrm{dc}$ full-bridge converter with flat efficiency under wide pv module voltage 
and load range," IEEE Trans. Ind. Electron., Vol. 55, No. 7, pp. 2655-2663, Jul. 2008.

[6] R.-J. Wai, W.-H. Wang, and C.-Y. Lin., "High-Performance Stand-Alone Photovoltaic Generation System," IEEE Trans. Ind. Electron., Vol. 55, No. 1, pp. 240-250, Jan. 2008.

[7] B.-D. Min, J.-P. Lee, J.-H. Kim, T.-J. Kim, D.-W. Yoo, and E.-H.-Song, "A new topology with high efficiency throughout all load range for photovoltaic pcs," IEEE Trans. on Industrial Electronics, Vol. 56, No. 11, pp 4427-4435, Nov. 2009.

[8] A. Dell'Aquila, M. Liserre, V. G. Monopoli, and P. Rotondo, "Overview of pi-based solutions for the control of $\mathrm{dc}$ buses of a single-phase h-bridge multilevel active rectifier," IEEE Trans. Ind. Appl., Vol. 44, No. 3, pp. 857-866, May/Jun. 2008.

[9] E. Vilanueva, P. Correa, J. Rodriguez, and M. Pacas, "Control of a single-phase cascaded h-bridge multilevel inverter for grid-connected photovoltaic systems," IEEE Trans. Ind. Electron., Vol. 56, No. 11, pp. 4399-4406, Nov. 2009.

[10] K. Kobayashi, H. Matsuo, and Y. Sekine "An excellent operating point tracker of the solar-cell power supply system," IEEE Trans. Ind. Electron., Vol. 53, No. 2, pp. 495-499, Apr. 2006.

[11] R. Kadri, J.-P. Gaubert, and G. Champenois, "an improved maximum power point tracking for photovoltaic grid-connected inverter based on voltage-oriented control ," IEEE Trans. Ind. Electron., Vol. 58, No. 1, pp. 66-75, Jan. 2011.

[12] L. A. C. Lopes and A.-M. Lienhardt, "A simplified nonlinear power source for simulating PV panels," IEEE 34th Power Electronics Specialist Conference, 2003, Vol. 4, 15-19, pp. 1729-1734, Jun. 2003.

[13] Q. Mei, M. Shan, L. Liu, and J. M. Guerrero, "A novel improved variable step-size incremental-resistance mppt method for pv systems," IEEE Trans. Ind. Electron., Vol. 58, No.6, pp. 2427-2434, Jun. 2011.

[14] L. Zhou, Y. Chen, K. Guo, and F. Jia, "New approach for mppt control of photovoltaic system with mutative-scale dual-carrier chaotic search," IEEE Trans. Power Electron., Vol. 26, No. 4, pp. 1038-1048, Apr. 2011.

[15] W. Xiao, N. Ozog, and W. G. Dunford, "Topology study of photovoltaic interface for maximum power point tracking," IEEE Trans. Ind. Electron., Vol. 54, No. 3, pp. 1696-1704, Jun. 2007.

[16] E. M. Ahmed and M. Shoyama, "Variable step size maximum power point tracker using a single variable for stand-alone battery storage pv systems," Journal of Power Electronics, Vol. 11, No. 2, pp. 218-227, Mar. 2011.

[17] J. Lee, B. Min, J. Kim, D. Yoo, and J. Yoo "The novel high efficiency grid-tied multi string pv pcs using h-bridge multi-level topology," $37^{\text {th }}$ Annual Conference on IEEE Industrial Electronics Society, IECON, pp. 1631-1635, Sep. 2011.

[18] Y.-M. Park, J.-Y. Yoo, and S.-B. Lee, "Practical implementation of pwm synchronization and phase-shift method for cascaded h-bridge multilevel inverters based on a standard serial communication protocol," IEEE Trans. Ind. Appl., Vol. 44, No. 2, Mar./Apr. 2008.

[19] H. Koizumi, T. Mizuno, T. Kaito, Y. Noda, N. Goshima, M. Kawasaki, K. Nagasaka, and K. Kurokawa, "A novel microcontroller for grid-connected photovoltaic systems," IEEE Trans. Ind. Electron., Vol. 53, No. 6, pp. 1889-1897, Dec. 2006.
[20] Y.-M. Park, H.-S. Ryu, H.-W. Lee, M.-G. Jung, and S.-H. Lee, "Design of a cascaded h-bridge multilevel inverter based on power electronics building blocks and control for high performance," Journal of Power Electronics, Vol. 10, No. 3, pp. 262-269, May 2010.

[21] J.-M. Kwon, B.-H. Kwon, and K.-H. Nam, "Grid-connected photovoltaic multistring pes with pv current variation reduction control," IEEE Trans. Ind. Electron., Vol. 56, No. 11, pp. 4381-4388, Nov. 2009.

[22] M. W. Davis, R. Broadwater, and J. Hambrick, "Modeling and testing of unbalanced loading and voltage regulation," NREL/SR-581-41805 Report, Jul. 2007.

[23] SMA Sunny Central 250-US Manual, http://www.sma-america.com/en_US/products/grid-tied-inv erters/sunny-central.html.

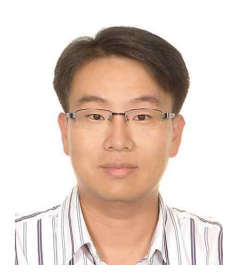

Jong-Pil Lee received his B.S. in Control and Instrumentation Engineering and his M.S. in Electrical Engineering from Korea University, Seoul, Korea, in 1997 and 1999, respectively. He also received his Ph.D. from the School of Electrical Engineering, Korea University, in 2012. From 1999 to 2005, he was a Senior Researcher at Hyundai Heavy Industries in the Electric and Hybrid Vehicle Research section. $\mathrm{He}$ has been working as a Senior Researcher in the Power Conversion and Control System Center of the HVDC Division of the Korea Electro-technology Research Institute (KERI), Changwon, Korea. His main research interests include photovoltaic PCS, PMSG wind turbine PCS, distributed power generation systems, and power conversion for HVDC systems.

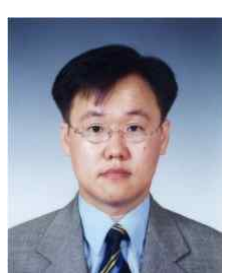

Byung-Duk Min received his B.S. in Electronic Engineering at Kyungpook National University, Daegu, Korea, in 1990, and his M.S. and Ph.D. in Electronic and Electrical Engineering at the Pohang University of Science and Technology (POSTECH), Pohang, Korea, in 1992 and 1997, respectively. He worked for Hyundai Electronics Industries and Hyundai Heavy Industries in the Electric and Hybrid Vehicle Research section from 1997 to 2004. He was a Senior Researcher in Renewable Research Group at the Korea Electro-technology Research Institute (KERI), Changwon, Korea, from 2005 to 2010 . He has been with Green Power Co., Ltd., since 2010. His main research interests include photovoltaic PCS, photovoltaic simulators, UPS, induction and PMSM motor drivers, and hybrid electric vehicle drivers.

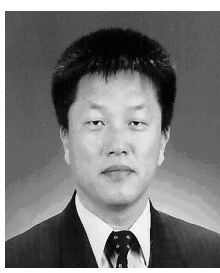

Dong-Wook Yoo received his B.S. in Electrical Engineering from Sungkyunkwan University (SKKU), Suwon, Korea, in 1983, his M.S. in Electrical Engineering from Yonsei University, Seoul, Korea, in 1985, and his Ph.D. in Power Electronics, from SKKU, in 1997. He became a Researcher in 1985, a Senior Researcher in 1989, and a Principal Researcher in 1997 at the Korea Electro-technology Research Institute (KERI), Changwon, Korea. He is currently the head of Power Conversion and Control Laboratory, and HVDC Research Division at KERI. His main research interests include photovoltaic PCS, wind turbine PCS, UPS, and power conversion for HVDC systems. 